\title{
Child-Sex Preference and Factors That Influenced Such Choices among Women in an Obstetric Population in Nigeria
}

\author{
Emmanuel C. Inyang-Etoh ${ }^{1}$, Anyiekere M. Ekanem ${ }^{2}$ \\ ${ }^{1}$ Department of Obstetrics and Gynecology, University of Uyo, Uyo, Nigeria \\ ${ }^{2}$ Department of Community Health, University of Uyo, Uyo, Nigeria \\ Email: *emmacol2000@yahoo.com
}

How to cite this paper: Inyang-Etoh, E.C. and Ekanem, A.M. (2016) Child-Sex Preference and Factors That Influenced Such Choices among Women in an Obstetric Population in Nigeria. Open Access Library Journal, 3: e3005.

http://dx.doi.org/10.4236/oalib.1103005

Received: September 25, 2016

Accepted: October 17, 2016

Published: October 25, 2016

Copyright $\odot 2016$ by authors and Open Access Library Inc.

This work is licensed under the Creative

Commons Attribution International

License (CC BY 4.0).

http://creativecommons.org/licenses/by/4.0/ (c) (i) Open Access

\begin{abstract}
Son preference is a global phenomenon that is influenced by personal, conjugal, socioeconomic and cultural factors. Objectives: This study was designed to determine child-sex preference of women among an obstetric population in Nigeria, and to obtain the reasons for such choices. Materials and Methods: A 15-item questionnaire was used to obtain information from the respondents on their child-sex preference and factors that influenced such preferences. Results: Four hundred and fifty-three women with a mean age of $29.07+4.70$ were surveyed. Most $(428,94.5 \%)$ were married, 448 (98.9\%) were Christians, 404 (89.2\%) were booked attending antenatal care in the centre, and $289(63.8 \%)$ had attained post-secondary level of education. The vast majority 294 (64.9\%) of the mothers preferred to have male children in the index pregnancy. About half 223 (49.2\%) of the mothers would stop trying to have their preferred child-sex after 4 attempts. The majority $(171,37.7 \%)$ of the mothers made their child-sex preference in order to attain gender balance in the family, while 129 (28.5\%) of them made their preference to ensure inheritance. Mothers whose reasons for child-sex preferred were "for inheritance", "to satisfy husband", and "to consolidate marriage" significantly preferred sons, $\mathrm{p}=0.000$. Conclusion: This study has confirmed Nigeria as a patriarchal society, where women prefer to have male children as against daughters, although, the trend was towards the attainment of child-sex balance in the composition of offspring in the family. Mothers' preferences for sons in this study were significantly influenced by patriarchal considerations.
\end{abstract}

\section{Subject Areas}

Gynecology \& Obstetrics 


\section{Keywords}

Mothers, Child-Sex, Preference, Reasons, Nigeria

\section{Introduction}

Nigeria, like most countries in Africa, Asia, Middle East and India, exhibits patrilineal and patriarchal family systems where sons exclusively inherit the wealth of the family and perpetuate family lines [1]-[3]. Daughters on the other hand, are seen as inferior to their male siblings as they would eventually be married out of the family [4] [5]. The high premium placed on sons by the family is due to their economic utility as they run the family businesses, earn wages to support the family, and when they marry, bring daughters in-law into the family [1] [2] [6]. In some cultures, certain religious and cultural rites can only be performed by the males; the advantages of daughters to the family are modest; they have been found to be more likely to perform house chores and to provide better emotional support to their parents [6] [7].

Son preference is a global phenomenon not peculiar to developing countries, although its prevalence in any given society may vary. In a patriarchal society like Nigeria, mothers are under intense pressure to give birth to sons in order to satisfy their husbands and consolidate their marriages [4] [5]. Mothers who give birth to only daughters are therefore unhappy because of the fear of disappointment and rejection by their husbands [4]. The anxiety associated with failure to have preferred child-sex has compelled many pregnant women to demand to know the sex of their unborn children during obstetric ultrasonography with significant reduction in birth interval whenever the fetal sex is not the type desired by such mothers [3] [5] [8].

Similarly, many have tended to have large family sizes in an attempt to have the desired child-sex in the family [3] [8]-[10]. While sex-selection abortion to ensure preferred offspring is still practiced by a minority of Chinese women, Nigerian women tend to accept an increase in their family size in an effort to attain gender balance in the family [9]-[11]. This phenomenon has reflected in the Nigerian national statistics, where Nigerian women have been found to desire large family sizes of 7.1 children for currently married women and 6.5 for all women [12]. Only $9 \%$ of Nigerian women consider 3 or less number of children as ideal [12]. The population of Nigeria in 2006 was $140,431,790$ with an average national growth rate of $3.2 \%$ per annum and a rather huge projected population of $182,824,841$ by 2016 [12]. Such rapid growth in national population is not unrelated to the quest for sons by Nigerian women. The sex ratio in Nigeria of 1.026, which is higher than the global sex ratio of 1.016 as at 2015, may also be a reflection of the effort in pursuit of more male offspring by Nigerian mothers [12].

Anecdotal evidence that grand multiparous mothers attending antenatal care in the University of Uyo Teaching Hospital, Nigeria had largely children of the same sex set the pace for this study, which was designed to survey child-sex preference of mothers attending antenatal care in the centre and the factors that influenced such choices. 


\section{Subjects and Methods}

\subsection{Study Design and Study Area}

This was a cross sectional questionnaire-based descriptive study of mothers who attended antenatal visits during a two month period from $1^{\text {st }}$ October to $30^{\text {th }}$ November 2015 in the Maternity unit of the University of Uyo Teaching Hospital, Uyo, Nigeria.

The University of Uyo Teaching hospital is the only tertiary level health care facility in Akwa Ibom State, located in the south-east health zone of Nigeria. The state has a population of 3.9 million people according to the Nigerian census conducted in 2006 and projected to 5.1 million people by 2015 [12]. Akwa Ibom state is one of the 36 states of the federal republic of Nigeria, and it has one federal university teaching hospital, 3 academic institutional medical centers, 16 general hospitals and 125 private clinics [13].

Uyo, the capital of Akwa Ibom State is inhabited largely by the Ibibios, the Annangs and the Oros, who are the indigenous tribes of the state living together with some other Nigerian tribes like the Igbos, Efiks, Yorubas, Hausas and Fulanis [12]. The people of the state are predominantly government employed civil servants, and other persons indulging in peasant farming, petty trading as well as small and medium scale businesses [12].

\subsection{Data Collection and Analysis}

Approval was obtained from the University of Uyo Teaching Hospital Ethical Committee before commencement of the study. Selected Resident doctors in the department were trained to serve as research assistants and to administer the questionnaires to women attending antenatal visits in the centre during the study period. The mothers were counseled on the purpose of the study and informed that participation in the study was voluntary. The freedom of the women to withdraw from the study at any time should they desire to do so was emphasized to them. Women who declined to participate in the study, those who were found to be emotionally unstable and anyone who had a mental illness were excluded from the study.

The questionnaire which was structured and partly pre-coded had been pretested among a cross section of 20 women attending antenatal care in St. Lukes's General Hospital a month earlier and necessary corrections made to improve the validity and reliability of the questions.

The questionnaires were administered by research assistants to a cross section of women attending antenatal care on every clinic day for the period of the study for self-completion. Respondents who were not literate were assisted through interpretation to complete the forms, and those who needed explanations, the research assistants attended to them. Questions were set to obtain the demographic and obstetric parameters of the respondents, the child-sex preference of the mothers in the index pregnancy, the reasons for such preference, the number of children of preferred sex desired, and how far they can go to have their preferred sex of children. For example, respondents were asked: what sex of baby would you prefer to have in this pregnancy? Girl or Boy. Why do you prefer that sex for your child? To satisfy my husband, to consolidate my 
marriage, to satisfy my in laws, for inheritance, for gender balance in the family, others, state. Would you opt for an abortion if ultrasound scan shows that your baby again has a sex you don't desire at the time? Yes or No. Examples of open ended questions asked were: How many children of your preferred sex would you want to have? After how many children would you stop attempting to have your preferred sex of child? A total of 8 questions were asked in order to test the respondents' child- sex preference and the reasons for such choices.

Data generated from the study were coded and entered into the software of the Statistical Package for Social Sciences (SPSS), Version 17 Inc. Chicago, Illinois, USA. Descriptive statistics were performed for continuous variables and deductions were made using descriptive and inferential statistics. Association between selected factors and child-sex preference among mothers in the study population were computed using the Chi squared test, and differences were considered significant at a p-value of less than 0.05.

\section{Results}

Four hundred and fifty-three (453) women attending antenatal care in the Maternity unit of the University of Uyo Teaching Hospital during the study period participated in the study. The mean age of respondents was $29.07 \pm 4.70$ years, mean height of $1.61 \pm$ $0.06 \mathrm{~m}$ and mean weight of $78.61 \pm 16.01 \mathrm{~kg}$. The proportion of mothers that would adopt children of preferred sex if they fail to have theirs was 47 (10.4\%), whereas 405 $(89.6 \%)$ would not. Mothers who would terminate pregnancy if the sex of child is not type preferred at the time were $9(2.0 \%)$, whereas $443(98.0 \%)$ would not. Table 1 shows the demographic and obstetric parameters of women in the study population. Most of the women were married 428 (94.5\%), Christians 448 (98.9\%) and booked 404 $(89.2 \%)$, receiving antenatal care in the centre. The vast majority $289(63.8 \%)$ had attained post-secondary level of education and 141 (31.1\%) of them were unemployed. The type of child- sex and number of such children preferred by the mothers in the study population are shown in Table 2. The majority 294 (64.9\%) of the mothers preferred male children with a comparable proportion 297 (65.6\%) preferring 2 children of the preferred sex. About half 223(49.2\%) of the mothers would stop trying to have their preferred child-sex after 4 attempts. As many as 81 (17.9\%) of the women would want to have 5 or more attempts before they give up on their effort to have their preferred child-sex. Table 3 shows the factors the influenced mothers' choices in this study. The majority 171 (37.7\%) of the women made their child- sex preference in order to attain gender balance in the family, while 129 (28.5\%) of them made their preference to ensure inheritance. Nearly half $221(48.8 \%)$ of the women's choices were influenced by desire to have a small family, followed by those 116 (25.6\%) who needed children who would take care of them in their old age. Religion 147 (32.5\%), personal reasons 136 (30.0\%) and socioeconomic factors 135 (29.8\%) were major factors that influenced women's choices about child-sex preference, the number of such children desired and the reasons for such choices. The presence of any association between selected factors and type of child-sex preferred by mothers in the study population was tested in Table 4. 
There were no significant association between educational level, booking status, religion, socioeconomic consideration and personal desire, and type of child-sex preferred by mothers in the study population. However, there was a highly significant association between some reasons for child-sex preference and the type of child-sex preferred by mothers. Mothers who made their child-sex preference for the following reasons, "for inheritance", "to satisfy husband", and "to consolidate marriage", significantly preferred male children $(\mathrm{p}=0.000)$.

\section{Discussion}

The quest for gender balance in Nigerian families by mothers has made its contribution to the prevailing large family units in the country, arising from personal, conjugal, religious and socioeconomic influences. This study population was made up of women of

Table 1. Demographic and obstetric characteristics of women in the study population.

\begin{tabular}{|c|c|c|}
\hline Demographic and obstetric characteristics & Number (n) & Percentage (\%) \\
\hline \multicolumn{3}{|l|}{$\underline{\text { Marital status }}$} \\
\hline Married & 428 & 94.5 \\
\hline Engaged & 14 & 3.1 \\
\hline single & 9 & 2.0 \\
\hline Widowed/divorced & 2 & 0.4 \\
\hline \multicolumn{3}{|l|}{$\underline{\text { Religion }}$} \\
\hline Christianity & 448 & 98.9 \\
\hline Islam & 5 & 1.1 \\
\hline \multicolumn{3}{|l|}{$\underline{\text { Educational level }}$} \\
\hline No formal education & 3 & 0.7 \\
\hline Primary secondary & 21 & 4.6 \\
\hline Secondary & 140 & 30.9 \\
\hline Post-secondary & 289 & 63.8 \\
\hline \multicolumn{3}{|l|}{ Occupation } \\
\hline Unemployed & 141 & 31.1 \\
\hline Unskilled & 114 & 25.2 \\
\hline Semiskilled & 56 & 12.4 \\
\hline Skilled/Technical & 127 & 28.0 \\
\hline Professional & 15 & 3.3 \\
\hline \multicolumn{3}{|l|}{$\underline{\text { Booking status }}$} \\
\hline Booked & 404 & 89.2 \\
\hline Unbooked & 38 & 8.4 \\
\hline Referred & 11 & 2.4 \\
\hline Total & 453 & 100.0 \\
\hline
\end{tabular}


Table 2. Type of child-sex and number of such children preferred by mothers in the study population.

\begin{tabular}{ccc}
\hline Types of child-sex preferred & Number (n) & Percentage (\%) \\
\hline Females & 159 & 35.1 \\
Males & 294 & 64.9 \\
No. of preferred children desired & & 6.4 \\
1 & 29 & 65.6 \\
2 & 297 & 21.9 \\
3 & 99 & 5.3 \\
4 & 24 & 0.8 \\
$\geq 5$ & 4 & \\
No. of children before stopping to attempt & & 0.0 \\
$\leq 2$ & 0 & 32.9 \\
3 & 149 & 49.2 \\
4 & 223 & 12.1 \\
5 & 55 & 5.8 \\
$\geq 6$ & 26 & 100.0 \\
\hline
\end{tabular}

Table 3. Factors that influenced mothers' preference of a particular sex of child.

\begin{tabular}{|c|c|c|}
\hline Factors & Number (n) & Percentage (\%) \\
\hline \multicolumn{3}{|l|}{ Reasons for preference } \\
\hline For gender balance in the family & 171 & 37.7 \\
\hline For inheritance & 129 & 28.5 \\
\hline To satisfy my husband & 80 & 17.7 \\
\hline To consolidate my marriage & 62 & 13.7 \\
\hline Others & 11 & 2.4 \\
\hline \multicolumn{3}{|l|}{ Reasons for choice of no. of preferred sex } \\
\hline I prefer a small family & 221 & 48.8 \\
\hline To care for me in my old age & 116 & 25.6 \\
\hline I prefer a large family & 41 & 9.1 \\
\hline To satisfy my husband & 28 & 6.2 \\
\hline In case of death & 24 & 5.3 \\
\hline Others & 23 & 5.0 \\
\hline \multicolumn{3}{|l|}{ Factors that influenced preferences } \\
\hline Religion & 147 & 32.5 \\
\hline Culture/Tradition & 35 & 7.7 \\
\hline socioeconomic & 135 & 29.8 \\
\hline Personal & 136 & 30.0 \\
\hline Total & 453 & 100.0 \\
\hline
\end{tabular}


Table 4. Association between selected factors and child- sex preference by mothers in the study population.

\begin{tabular}{|c|c|c|c|c|}
\hline \multirow{3}{*}{ Factors } & \multicolumn{4}{|c|}{ Sex preference } \\
\hline & \multicolumn{2}{|c|}{$\underline{\text { Female }}$} & \multicolumn{2}{|c|}{$\underline{\text { Male }}$} \\
\hline & (No.) & (\%) & (No.) & $(\%)$ \\
\hline Educational level & \multicolumn{4}{|c|}{$\mathrm{X}^{2}=3.355, \mathrm{df}=3, \mathrm{p}=0.384$} \\
\hline No formal education & 0 & 0.0 & 3 & 1.0 \\
\hline Primary & 10 & 6.3 & 11 & 3.7 \\
\hline Secondary & 51 & 32.1 & 89 & 30.3 \\
\hline Post-secondary & 98 & 61.6 & 192 & 65.0 \\
\hline Booking status & \multicolumn{4}{|c|}{$\mathrm{X}^{2}=2.803, \mathrm{df}=2, \mathrm{p}=0.237$} \\
\hline Booked & 145 & 91.2 & 259 & 88.1 \\
\hline Unbooked & 9 & 5.7 & 29 & 9.9 \\
\hline Referred & 5 & 3.1 & 6 & 2.0 \\
\hline Reasons for preferred child-sex & \multicolumn{4}{|c|}{$\mathrm{X}^{2}=25.912, \mathrm{df}=5, \mathrm{p}=0.000$} \\
\hline For gender balance in family & 85 & 53.5 & 86 & 29.3 \\
\hline For inheritance & 35 & 22.0 & 94 & 32.0 \\
\hline To satisfy my husband & 21 & 13.2 & 59 & 20.1 \\
\hline To consolidate my marriage & 15 & 9.4 & 47 & 16.0 \\
\hline \multicolumn{5}{|l|}{ Other factors } \\
\hline Religion & \multicolumn{4}{|c|}{$\mathrm{X}^{2}=0.934, \mathrm{df}=1, \mathrm{p}=0.346$} \\
\hline Yes & 47 & 32.0 & 100 & 68.0 \\
\hline No & 112 & 36.6 & 194 & 63.4 \\
\hline Socioeconomic consideration & \multicolumn{4}{|c|}{$\mathrm{X}^{2}=0.946, \mathrm{df}=1, \mathrm{p}=0.334$} \\
\hline Yes & 37 & 23.3 & 57 & 19.4 \\
\hline No & 122 & 76.7 & 237 & 80.6 \\
\hline Personal desire & \multicolumn{4}{|c|}{$\mathrm{X}^{2}=0.040, \mathrm{df}=1, \mathrm{p}=0.916$} \\
\hline Yes & 51 & 34.5 & 97 & 65.5 \\
\hline No & 108 & 35.1 & 197 & 64.6 \\
\hline
\end{tabular}

reproductive age with a mean age of 29.07 years, comparable to a mean age of 31.97 years among respondents in a similar study conducted in Tharu community from rural area of eastern region of Nepal [8]. Most of the women in the study population were married, Christians, had booked and were receiving antenatal care, and 289(63.8\%) of them had attained post-secondary level of education. This profile is common to obstetric populations in southern Nigeria [5] [8] [14] [15]. In contrast, due to sociocultural differences, obstetric populations in northern Nigeria usually comprise largely younger Muslim women with lower levels of education [16].

The vast majority 294 (64.9\%) of women in the study population preferred to have 
sons in the index pregnancy, with 297(65.6\%) desiring to have 2 children of their preferred sex and opting to stop after 4 attempts if their preferred sex was not obtained. This trend among Nigerian women is suggestive of a desire for gender balance in the family rather than an exclusive preference for sons. While the phenomenon of son preference by families in China has weakened considerably, in Bangladesh and most Western countries, the trend is towards a balanced gender composition in the family, similar to what was found in this study [7] [11] [17] [18]. The reason for child sex preference by the majority of mothers in the study population was to attain gender balance 171 (37.7\%) in the family or to ensure inheritance 129 (28.5\%). Since Nigeria is a patriarchal society, this result was not surprisingly because these women might have preferred sons for the peculiar roles sons play in the family as adduced by other similar studies [4] [7]. This rather global phenomenon occurs in countries like Nigeria against the backdrop that it contributes to short birth interval, low utilization of contraception, escalation of national population growth, and some authorities have identified it as a violation of women's reproductive health rights [1] [3] [4] [8] [10].

Interestingly, only $47(10.4 \%)$ of women in the study population would adopt children of their preferred sex if they fail to have theirs due to the perception of child adoption by Nigerian women as a failure of womanhood [19]. Similarly, as few as 9 (2\%) of the mothers in the study population would terminate pregnancy if prenatal ultrasound scan reveals a child-sex not desirable to the mother at the time, because they perceive children as gifts from God [20]. In addition, Nigeria has a restrictive abortion law, which prescribes stiff penalty for any person convicted for committing a non-therapeutic abortion [21].

Among selected factors tested for any association between the type of child-sex preferred by mothers in the study population, only the reasons for preference like, "for inheritance", "to satisfy husband" and "to consolidate marriage" were highly significant and skewed in favor of male children $(\mathrm{p}=0.000)$. This finding has corroborated results from other studies conducted in patriarchal societies like Nigeria [5] [7] [22]. This trend if not checked could have negative socioeconomic and cultural consequences in affected societies [4] [8] [17] [23]. The limitation of this study is the fact that its results may not be a true representation of the situation in the general Nigerian population since a convenient sampling technique was used to draw up the study population, notwithstanding, the results have provided insight into the child-sex preference of a cross section of Nigerian mothers and the reasons for such choices. Since Nigerian mothers would not mind large families in order to attain a balance in the offspring composition, clinicians have to brace up to tackle possible obstetric complications that might be associated with grand multiparity. Government has a role to play through public enlightenment and legislation to encourage Nigerians to accept their children and treat them equally irrespective of their sex. The need for a research to focus on the perception and attitude of men towards child-sex preference has become imperative with the revelation that mothers' choices as regards child-sex were influenced by what they perceived as the feelings and attitude of their husbands towards child-sex. 


\section{Conclusions}

This study has confirmed Nigeria as a patriarchal society where the majority of mothers preferred to have sons as against daughters, although, the trend was towards the attainment of child-sex balance in the composition of offspring in the family. This global phenomenon was influenced by personal, religious and socioeconomic factors among Nigerian mothers, although patriarchal considerations like desire to secure inheritance, desire to satisfy husband and desire to consolidate ones marriage significantly influenced preference for sons by mothers in the study population.

Government has a role to play through public enlightenment and legislation to encourage Nigerians to accept their children and treat them equally irrespective of their sex.

\section{Acknowledgements}

We wish to put on record our sincere gratitude to all the resident doctors who served as research assistants by administering questionnaires to the respondents. Our thanks also go to the antenatal clinic nurses of the centre for their support and co-operation during the period of the study.

\section{Conflict of Interest}

We declare no conflict of interest between us the authors of the research.

\section{References}

[1] Ushie, A.M., Enang, E.E. and Ushie, C.A. (2013) Implications of Sex Preference for Population Growth and Maternal Health in Obudu and Obanliku, CRS, Nigeria. Academic Research International, 3, 492-501.

[2] Mutharayappa, R., Choe, M.K., Arnold, F. and Roy, T.K. (1997) Son Preference and Its Effects on Fertility in India. International Institute for Population Sciences, Mumbai.

[3] Fayehun, O.A., Omololu, O.O. and Isiugo-Abanihe, U.C. (2011) Sex of Preceding Child and Birth Spacing among Nigerian Ethnic Groups. African Journal of Reproductive Health, 2, 79-90.

[4] Nnadi, I. (2013) Son Preference-A Violation of Women's Human Rights: A Case Study of Igbo Customs in Nigeria. Journal of Politics and Law, 1, 134-141. http://dx.doi.org/10.5539/jpl.v6n1p134

[5] Ohagwu, C.C., Eze, C.C., Eze, J.C., Odo, M.C., Abu, P.O. and Ohagwu, C.I. (2014) Perception of Male Gender Preference among Pregnant Igbo Women. Annals of Medical and Health Sciences Research, 4, 173-178. http://dx.doi.org/10.4103/2141-9248.129027

[6] Dharmalingam, A. (1994) Old Age Security: Expectations and Experiences in a South Indian Village. Population Studies: Journal of Demography, 48, 5-19. http://dx.doi.org/10.1080/0032472031000147446

[7] Chhetri, U.D., Ansian, I., Bandary, S. and Adhikari, N. (2011) Sex Preference among Mothers Delivering at Patan Hospital. Kathmandu University Medical Journal, 9, 229-232.

[8] Rai, P., Pandel, I.S., Ghimire, A., Pokharel, P.K., Rijal, R. and Niraula, S.R. (2014) Effect of Gender Preference on Fertility: Cross Sectional Study among Women of Tharu Community from Rural Area of Eastern Region of Nepal. Reproductive Health, 11, 11-15. http://dx.doi.org/10.1186/1742-4755-11-15 
[9] Unger, J.B. and Molina, G.B. (1997) Desired Family Size and Son Preference among Hispanic Women of Low Socioeconomic Status. Family Planning Perspectives, 29, 284-287. http://dx.doi.org/10.2307/2953419

[10] Mace, R. and Sear, R. (1997) Birth Interval and Sex of Children in a Traditional African Population: An Evolutionary Analysis. Journal of Biosocial Science, 29, 499-507. http://dx.doi.org/10.1017/S0021932097004999

[11] Zhou, C., Wang, K.L., Zhou, X.D. and Hesketh, T. (2012) Son Preference and Sex-Selection Abortion in China: Informing Policy Options. International Journal of Public Health, 57, 459-465. http://dx.doi.org/10.1007/s00038-011-0267-3

[12] National Population Commission (NPC) Nigeria (2015) National Demographic and Health Survey (NDHS). Final Report of National Statistics, Abuja.

[13] Akwa Ibom State Ministry of Health (AKSMOH) (2015) Number of Health Facilities and Health Personnel in the State. Updated statistics of the Akwa Ibom State Ministry of Health for the Year 2015.

[14] Ngwan, S.D., Mohammad, H., Edem, B.E., Hwande, T.S. and Eke, B. (2014) Profile of Women Seeking to Know Fetal Sex at Ultrasound in a Nigerian Obstetric Population. Journal of Dental and Medical Sciences, 11, 90-93.

[15] Okeke, T.C., Enwereji, J.O., Okoro, O.S., Iferikigwe, E.S., Ikeako, L.C., Ezenyeaku, C.C. and Adiri, C.O. (2015) Desire for Prenatal Gender Disclosure among Primigravidae in Enugu, Nigeria. Patient and Adherence, 9, 429-433. http://dx.doi.org/10.2147/PPA.S77029

[16] Maaji, S.B., Ekele, B.A., Bello, S.O. and Morhason-Bello, I.O. (2010) Do Women Want Disclosure of Fetal Gender during Prenatal Ultrasound Scan? Annals of African Medicine, 1, 11-14.

[17] Rahman, M., Akbar, J., Phillips, J.F. and Becker, S. (1992) Contraceptive Use in Matlab, Bangladish: The Role of Gender Preference. Studies in Family Planning, 23, 229-242. http://dx.doi.org/10.2307/1966885

[18] Van Balen, F. (2006) Attitudes towards Sex Selection in the Western World. Prenatal Diagnosis, 26, 614-618. http://dx.doi.org/10.1002/pd.1471

[19] Omosun, A.O. and Kofoworola, O. (2011) Knowledge, Attitude and Practice towards Child Adoption among Women Attending Infertility Clinics in Lagos, Nigeria. African Journal of Primary Health Care \& Family Medicine, 3, 259-319. http://dx.doi.org/10.4102/phcfm.v3i1.259

[20] Pathfinder International (2010) Reproductive Health Knowledge and Practices in Northern Nigeria: Challenging Misconceptions. Reproductive Health/Family Planning Services Project Report, 11-15.

[21] Population Report (1980) Pregnancy Termination Complications of Abortion in Developing Countries. Population Report Series, 7-11.

[22] Kaba, A.J. (2015) Explaining the Rapid Increase in Nigeria's Sex Ratio at Birth: Factors and Implications. African Journal of Reproductive Health, 19, 17-33.

[23] Puri, S., Adams, V., Ivey, S. and Nachtigall, R.D. (2011) "There Is Such a Thing as Too Many Daughters, but Not Too Many Sons": A Qualitative Study of Son Preference and Fetal Sex Selection among Indian Immigrants in the United States. Social Science \& Medicine, 72, 1169-1176. http://dx.doi.org/10.1016/j.socscimed.2011.01.027 